\title{
KEPEMIMPINAN TRANSFORMASIONAL, BUDAYA ORGANISASI DAN KOMPENSASI TERHADAP LOYALITAS PEGAWAI
}

\author{
Muliati \\ STIE Tri Dharma Nusantara \\ Muliatiabbas12@gmail.com
}

\begin{abstract}
Abstrak
Penelitian ini bertujuan untuk menguji pengaruh kepemimpinan transformasional, budaya organisasi dan kompensasi terhadap loyalitas pegawai. Data dikumpulkan melalui kuesioner yang dibagikan kepada pegawai tetap PT Bosowa Berlian Motor (BBM) yang berkerja minimal 8 tahun saat penelitian dilakukan sebanyak 39 orang. Adapun sampel penelitian menggunakan sampel jenuh. Metode analisis digunakan adalah regresi linier berganda melalui SPSS. Hasil penelitian ini menunjukkan bahwa kepemimpinan transformasional, budaya organisasi dan kompensasi signifikan memengaruhi loyalitas pegawai.
\end{abstract}

Kata kunci: kepemimpinan transformasional, budaya organisasi, kompensasi, loyalitas pegawai

\begin{abstract}
This study aims to examine the effect of transformational leadership, organizational culture and compensation on employee loyalty. Data were collected through questionnaires distributed to permanent employees of PT Bosowa Berlian Motor (BBM) who had worked for at least 8 years when the research was conducted as many as 39 people. The research sample uses saturated samples. The analytical method used is multiple linear regression through SPSS. The results of this study indicate that transformational leadership, organizational culture and compensation significantly affect employee loyalty.
\end{abstract}

Keywords : transformational leadership, organizational culture, compensation, employee loyalty

\section{PENDAHULUAN}

Sumber daya manusia sangat menentukan keberhasilan pelaksanaan kegiatan perusahaan. Oleh karena itu, dalam mencapai tujuan perusahaan diperlukan pemimpin yang dapat memberikan inspirasi dan motivasi untuk membangun loyalitas karyawan. Jika perusahaan mendapat dukungan karyawan yang sangat terampil dan setia, maka perusahaan akan berkembang.

Perusahaan sangat membutuhkan loyalitas karyawan terhadap perusahaan. Loyalitas adalah cara karyawan dalam mencurahkan tenaga, waktu, kemampuan dan keterampilannya untuk perusahaan. Jika perusahaan tidak memiliki karyawan yang sangat loyal maka akan sangat sulit untuk mengembangkan perusahaan. Perusahaan harus bekerja keras untuk meningkatkan loyalitas karyawannya agar perusahaan dapat bertahan walaupun di masa-masa sulit.

PT Bosowa Berlian Motor (BBM) sebagai salah satu anak perusahaan dari Bosowa Grup yang bergerak dalam bisnis otomotif, sebagai dealer Mitsubishi untuk Kawasan Timur Indonesia tentu mempunyai kontribusi pada perkembangan Bosowa secara keseluruhan. Berdasarkan data penjualan Mitsubishi X-Pander sebanyak 12.374 
unit di tahun 2017, kemudian di tahun 2018 penjualan naik drastis sebanyak 75.075 unit dan 2019 turun sebanyak 62.666 unit. (otomotif.tempo.co.2020)

Naik turunnya penjualan berdampak pada profit sehingga sangat diharapkan loyalitas pegawai harus maksimal agar mampu menghasilkan profit yang maksimal pula. Oleh karena itu, perusahaan harus memperhatikan unsur-unsur yang memengaruhi loyalitas karyawan, dan karyawan bekerja di bawah pengawasan atasannya. Kepemimpinan transformasional sebagai pemimpin yang berhasil membuat karyawan secara langsung melampaui kepentingannya sendiri, Indikator kepemimpinan transformasional diukur dari karisma, motivasi inspirasional, perhatian pribadi, dan stimulasi intelektual.

(Marzuki, 2018) menyatakan gaya kepemimpinan tranformasional sangat efektif berupaya membangun semangat bawahan untuk committed dalam menciptakan visi dan tujuan bersama suatu instansi atau perusahaan. Pemimpin transformasional memberikan dukungan dan dorongan saat dibutuhkan untuk mempertahankan antusiasme dan menghadapi rintangan, kesulitan, dan kelelahan.

Hasil penelitian (Jaya, 2018), (Utami \& Inayah, 2019) dan (Nurhidayanti. S \& Jumarding, 2020) menemukan bahwa kepemimpinan transformasional berpengaruh signifikan terhadap Loyalitas pegawai. (Djuraidi \& Laily, 2020) menyatakan bahwa kepemimpinan transformasional merupakan pemimpin yang kharismatik dan mempunyai peran sentral serta strategi dalam membawa organisasi mencapai tujuannya.

Faktor lain yang memengaruhi loyalitas pegawai yakni budaya organisasi. (Gunawan, 2017) menyatakan bahwa budaya organisasi merupakan model, norma, keyakinan, dan nilai yang berlaku bagi perusahaan, model, norma, keyakinan dan nilai tersebut dapat mempengaruhi perilaku atau perilaku sumber daya manusia atau karyawan dalam organisasi atau perusahaan sehingga mempengaruhi loyalitas karyawan.

Di perusahaan, pemimpin tentu memiliki kekuasaan yang luas untuk mengambil keputusan dan mengatur bawahannya, serta menggunakan budaya yang dia pegang. Budaya organisasi dibentuk oleh individu-individu dalam organisasi dengan cara yang beretika dan memberikan hak kepada pegawai agar dapat fokus untuk mencapai tujuan organisas. Budaya organisasi yang baik dari pimpinan akan cenderung mendapatkan loyalitas dari karyawannya.

Hasil penelitian (Sugiyarto, 2017), (Asriandi, Gani, \& Hasbi, 2018) dan (Rose, 2019) menemukan bahwa budaya organisasi berpengaruh signifikan terhadap loyalitas. (Lumingkewas, Adolfina, \& Uhing, 2019) menyatakan budaya organisasi yang memberikan kebebasan kepada karyawan untuk menjalankan tugasnya, atau tidak memberikan tekanan kepada mereka untuk menjalankan tugasnya, sehingga meningkatkan loyalitas pegawai dan berdampak positif pada kinerja mereka.

Faktor lain yang mempengaruhi loyalitas pegawai yaitu kompensasi. (Dessler, 2015). Karyawan menerima gaji, tunjangan makan, tunjangan transportasi, asuransi kesehatan dan tunjangan hari raya sehingga santunan yang diterima dirasa cukup untuk memenuhi kebutuhan materi, maka kompensasi tersebut secara otomatis akan mempengaruhi loyalitas kerja karyawan. (Saptarini \& Yudhaningsih, 2020). Kompensasi karyawan mencakup semua bentuk pembayaran kepada karyawan yang menjadi hak hubungan kerja mereka.

(Gunawan, 2017) menyatakan kompensasi merupakan sesuatu yang diterima karyawan sebagai pengganti kontribusi jasa mereka pada perusahaan. Setiap karyawan 
dalam suatu organisasi mempunyai keinginan untuk mendapatkan kompensasi yang sesuai dengan harapan mereka. Apabila harapan tersebut terpenuhi, maka karyawan tersebut akan senantiasa loyal dalam bekerja.

Hasil penelitian terdahulu yang dilakukan oleh (Heryati, 2016), (Widi, 2018) dan (Purnamasari \& Sintasasih, 2019) menemukan bahwa kompensasi berpengaruh positif dan signifikan terhadap loyalitas pegawai. Semakin baik kompensasi yang diterima pegawai akan memperkuat loyalitasnya. Namun, berbeda dengan hasil penelitian yang dilakukan Triono (2018) Kompensasi berpengaruh positif dan tidak signifikan terhadap loyalitas kerja pegawai.

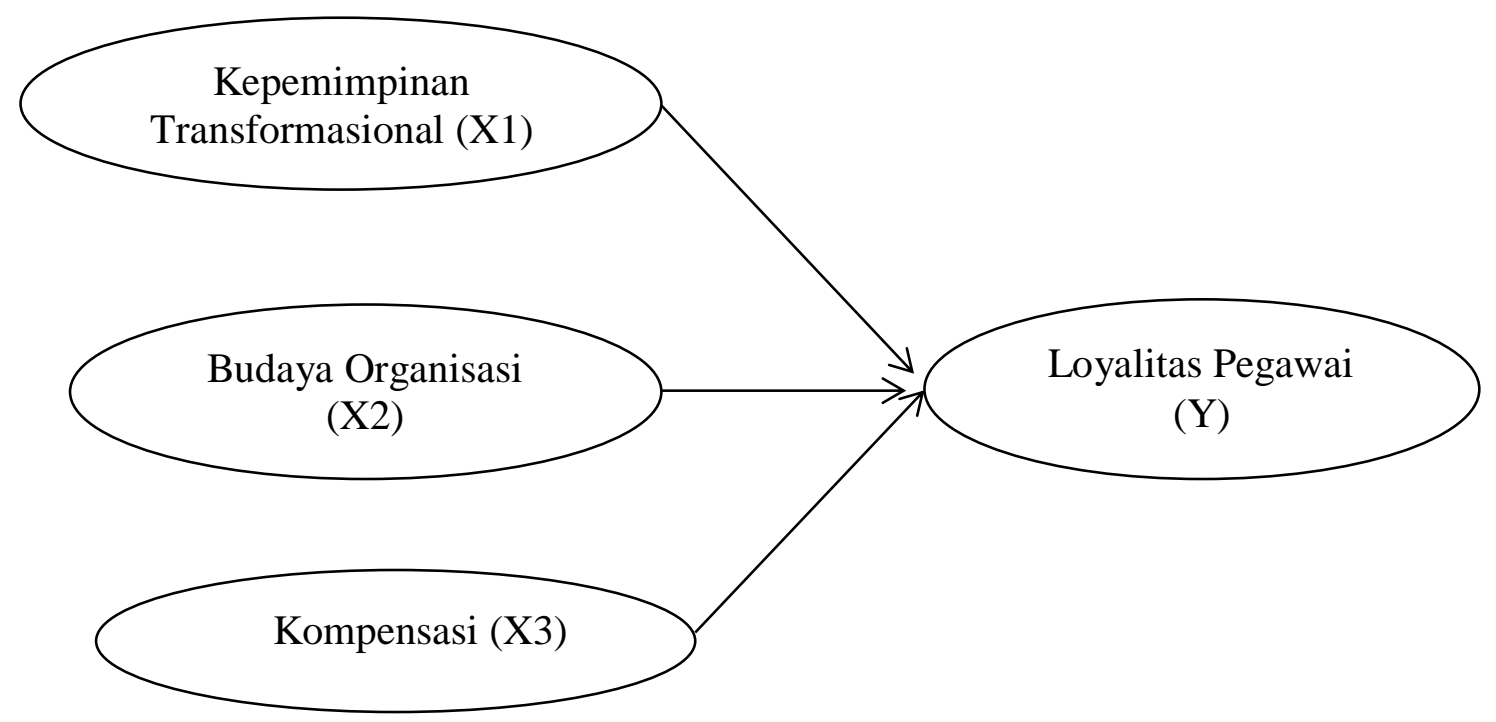

\section{Hipotesis}

Gambar 1. Kerangka Konseptual

Hipotesis penelitian ini yaitu :

$\mathrm{H}_{1} \quad$ : Kepemimpinan Transformasional positif signifikan memengaruhi loyalitas pegawai.

$\mathrm{H}_{2}$ : Budaya Organisasi positif signifikan memengaruhi loyalitas pegawai.

$\mathrm{H}_{3} \quad$ : Kompensasi signifikan memengaruhi loyalitas pegawai.

\section{METODE PENELITIAN}

\section{Pendekatan Penelitian}

Jenis penelitian yang digunakan adalah explanatory research, yaitu menjelaskan hubungan kausal antara variabel-variabel penelitian melalui pengembangan pengujian hipotesis.

\section{Metode Pengumpulan Data}


Teknik pengumpulan data dalam penelitian ini menggunakan kuesioner yang didistribusikan secara langsung kepada responden. Kuesioner merupakan daftar pertanyaan bertujuan sebagai alat bantu untuk mengumpulkan data variabel penelitian, yaitu dengan cara menyebarkan serangkaian pertanyaan tertulis kepada responden. Kuesioner yang disusun dengan Skala Likert 5 poin.

Analisis data penelitian ini dilakukan dengan beberapa tahap analisis yaitu : 1) Uji Statistik Deskriptif, 2) Uji normalitas melalui grafik Normal Probability Plot untuk melihat model regresi variabel dependen (terikat) dan variabel independen (bebas) memiliki kontribusi normal. 3) Uji multikolinearitas diperlukan untuk mengetahui ada tidaknya variabel independen yang memiliki kemiripan dengan variabel independen lain dalam satu model. 3) uji heteroskedastisitas bertujuan untuk menguji apakah dalam model regresi terjadi ketidaksamaan variance dan residual satu observasi ke observasi lain (Ghozali, 2016). Kemudian, untuk menguji hubungan antara variabel maka penelitian ini melakukan analisis regresi berganda melalui program SPSS dengan persamaan berikut :

$$
\mathrm{Y}=\alpha+\beta 1 \mathrm{X} 1+\beta 2 \mathrm{X} 2+\beta 3 \mathrm{X} 3+\mathrm{e}
$$

Keterangan :

$\alpha$ : Konstanta.

$\beta$ : Koefisien Regresi.

e : Error.

Y : Loyalitas Pegawai

$\mathrm{X} 1$ : Kepemimpinan transformasional

$\mathrm{X} 2$ : Budaya organisasi

X3 : Kompensasi

\section{Populasi dan Teknik Pengambilan Sampel}

Populasi dalam penelitian ini adalah seluruh pegawai tetap PT Bosowa Berlian Motor (BBM) di setiap bagian yang telah bekerja minimal 8 tahun ke atas dengan jumlah sampel 39 orang. Teknik sampel yang digunakan yakni sampel jenuh yakni smeua pupulasi adalah sampel.

\section{HASIL DAN PEMBAHASAN}

\section{Hasil Statistik Deskriptif}

Tabel 1. Statistik Deskriptif

\begin{tabular}{lrrrrr}
\hline \multicolumn{7}{c}{ Descriptive Statistics } \\
\hline X1 & \multicolumn{2}{c}{ Minimum } & Maximum & Mean & Std. Deviation \\
X2 & 39 & 2.50 & 4.88 & 4.2172 & .55917 \\
X3 & 39 & 3.00 & 5.00 & 4.2077 & .55561 \\
Y & 39 & 3.13 & 5.00 & 4.1910 & .47877 \\
& 39 & 2.63 & 5.00 & 4.2705 & .61372
\end{tabular}


Sumber : Data Diolah SPSS V. $23.00(2020)$

Output Tabel 7 menunjukan hasil analisis deskriptif :

a. Variabel kepemimpinan transformasional dengan nilai minimum 2,50 dan nilai maksimum 4,88 mencapai nilai rata-rata 4,217 dengan standar deviasi sebesar 0,559 .

b. Variabel budaya organisasi dengan nilai minimum 3,00 dan nilai maksimum 5,00 mencapai nilai rata-rata 4,207 dengan nilai standar deviasi sebesar 0,555.

c. Variabel kompensasi dengan nilai minimum 3,13 dan nilai maksimum 5,00 mencapai nilai rata-rata 4,191 dengan standar deviasi sebesar 0,478.

d. Variabel loyalitas pegawai dengan nilai minimum 2,63 dan nilai maksimum 5,00 mencapai nilai rata-rata 4,270 dengan standar deviasi sebesar 0,613.

Dari hasil statistik deskriptif di atas dapat dilihat respon dari responden atas pertanyaan disetiap variabel bervariasi.

\section{Hasil Uji Normalitas}

Hasil uji normalitas data dengan uji grafik normal probability plot, menunjukkan bahwa data dalam penelitian layak digunakan dan dikatakan normal, hal ini nampak pada gambar berikut :

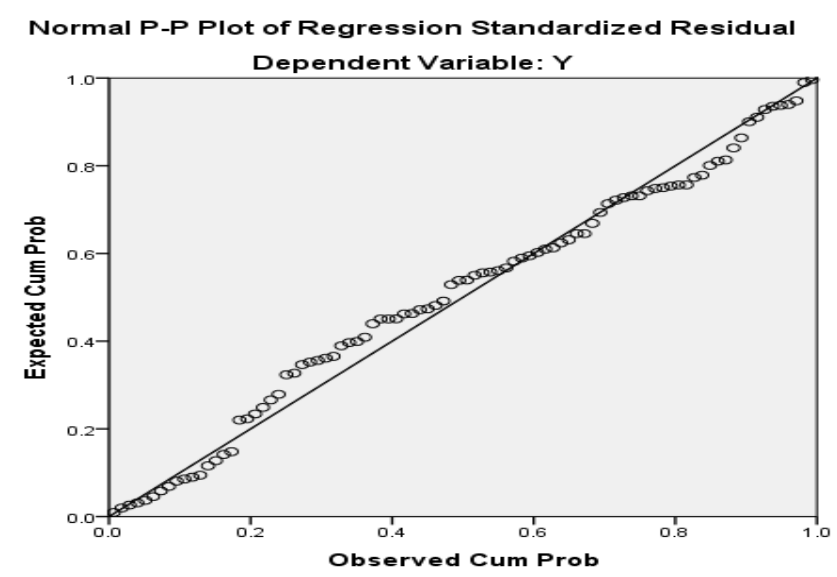

Gambar 2. Hasil Uji Normalitas

Sumber : Data Diolah SPSS V. 23.00 (2020)

\section{Hasil Uji Multikolinearitas}

Jika variabel independen berkorelasi tinggi maka hubungan antara variabel independen dengan variabel dependen akan terganggu. Untuk menguji multikolinearitas dapat dilihat dari nilai toleransi dan nilai VIF (variance inflation factor). Jika nilai VIF tidak lebih besar dari 10 dan nilai toleransinya tidak kurang dari 0,1 maka dapat dikatakan model tidak memiliki multikolinieritas.

Tabel 2. Hasil Uji Multikolinearitas 


\begin{tabular}{ccc}
\hline \multirow{2}{*}{ Model } & \multicolumn{2}{c}{ Collinearity Statistics } \\
\cline { 2 - 3 } & Tolerance & VIF \\
\hline X1 &, 172 & 5,801 \\
X2 &, 250 & 4,005 \\
X3 &, 265 & 3,769 \\
\hline Sumber : Data Diolah SPSS V. 23.00 (2020)
\end{tabular}

Dari hasil pengujian multikolinearitas data di atas memperlihatkan persamaan dapat ditoleransi dan keberadaannya tidak mengganggu model dibuktikan dengan nilai Varians Inflating Factors (VIF) ketiga variabel bebas yaitu : kepemimpinan transformasional sebesar 5,801, budaya organisasi sebesar 4,005 dan kompensasi sebesar 3,769, dimana ketiga variabel bebas tersebut mempunyai nilai VIF lebih kecil dari 10 dan nilai toleransinya lebih besar dari 0,1 .

\section{Hasil Pengujian Heteroskedastisitas}

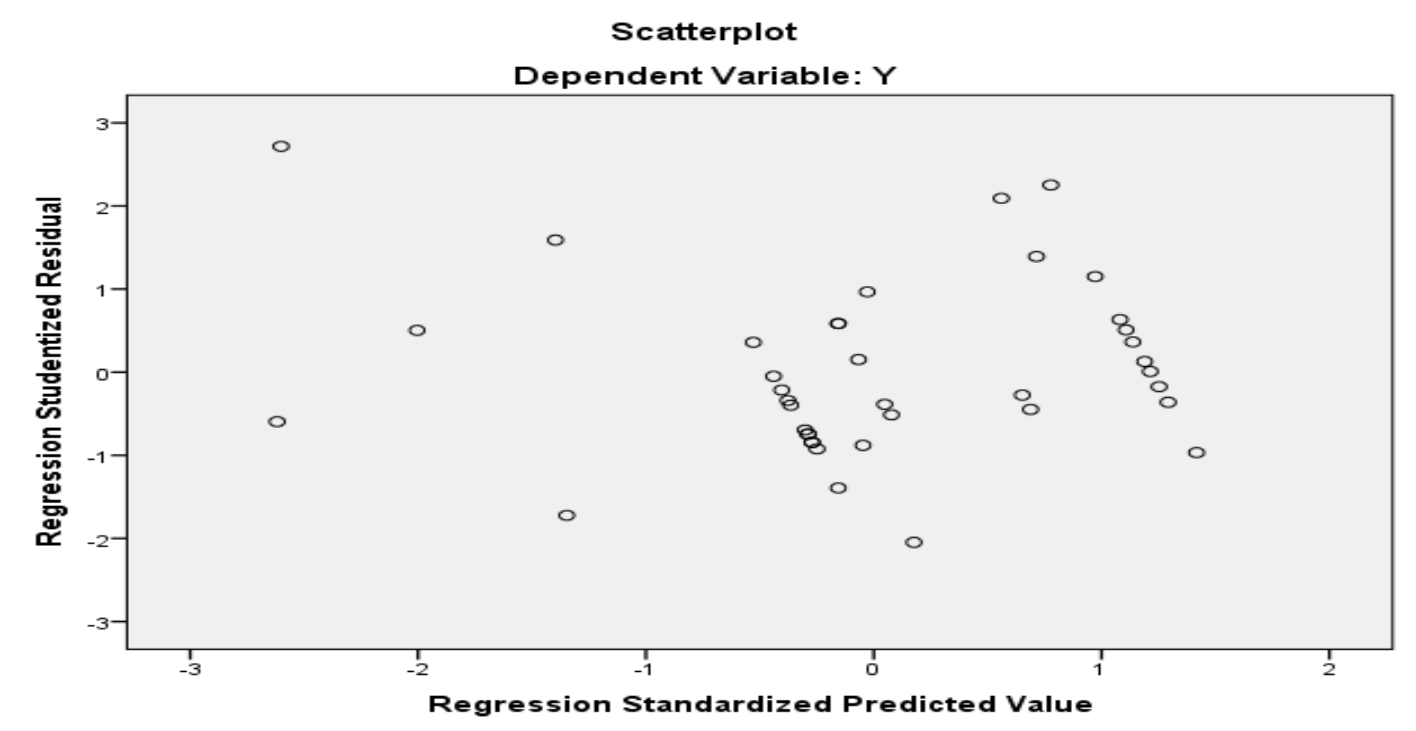

Gambar 3. Hasil Uji Heteroskedastisitas

Sumber : Data Diolah SPSS V. 23.00 (2020)

Grafik scatterplot yang ditampilkan pada gambar 3 menunjukkan bahwa data tersebar pada sumbu Y dan tidak membentuk suatu pola yang jelas dalam penyebaran data tersebut. Hal ini menunjukkan bahwa tidak terjadi heterokedaktisitas pada model regresi tersebut, sehingga model regresi layak digunakan untuk memprediksi loyalitas pegawai dengan variabel yang mempengaruhi yaitu kepemimpinan transformasional, budaya organisasi dan kompensasi.

\section{Hasil Pengujian Hipotesis}

Tabel 3. Hasil Uji Koefisien Determinasi Model Summary ${ }^{b}$ 


\section{AkMen \\ Volume 17 Nomor 4 Desember 2020 \\ Hal. 518 - 528 \\ e-ISSN : 2621-4377 \& p-ISSN : 1829-8524 \\ Hbmepage: https//e-jurnal.stienobel-indonesia.acid/indexphp/akmen}

\begin{tabular}{rrrrr}
\hline Model & R & R Square & $\begin{array}{c}\text { Adjusted R } \\
\text { Square }\end{array}$ & $\begin{array}{c}\text { Std. Error of the } \\
\text { Estimate }\end{array}$ \\
\hline 1 & $.979^{\mathrm{a}}$ & .957 & .953 & .13320 \\
\hline
\end{tabular}

a. Predictors: (Constant), X1, X2, X3

b. Dependent Variable: Y

Sumber : Data diolah SPSS V.23.00 (2020)

Nilai $\mathrm{R}$ square $\left(\mathrm{R}^{2}\right)$ yang diperoleh adalah 0,957 atau $95,70 \%$ menjelaskan loyalitas pegawai dipengaruhi oleh kepemimpinan transformasional, budaya organisasi dan kompensasi 95,70\%.

Tabel 4. Hasil Uji Simultan

\begin{tabular}{lrrrrr}
\multicolumn{8}{c}{ ANOVA $^{\text {a }}$} \\
\multicolumn{1}{c}{ Sum of } & \multicolumn{6}{c}{} & & \\
Squares & Df & Mean Square & F & Sig. & \\
\hline Regression & 13.692 & 3 & 4.564 & 257.228 & $.000^{\text {b }}$ \\
Residual & .621 & 35 & .018 & & \\
Total & 14.313 & 38 & & & \\
\hline
\end{tabular}

a. Dependent Variable: Y

b. Predictors: (Constant), X3, X2, X1

Sumber : Data diolah SPSS V.23.00 (2020)

Output tabel 4 menunjukkan nilai probability values pada kolom Sig menunjukkan nilai .000 atau probabilitas sebesar 0,000 dengan taraf signifikansi 5\%, maka variabel kepemimpinan transformasional, budaya organisasi dan kompensasi yang digunakan penelitian ini secara bersama-sama memengaruhi loyalitas pegawai.

Tabel 5. Hasil Uji Parsial (Uji t)

\begin{tabular}{ccccc}
\hline Model & $\begin{array}{c}\text { Unstandardized } \\
\text { Coefficients } \\
\mathrm{B}\end{array}$ & $\mathrm{T}$ & Sig. & Keputusan \\
\hline (Constant) & -.598 & & & \\
X1 & .531 & 5.709 & .000 & Hipotesis diterima \\
X2 & .443 & 5.693 & .000 & Hipotesis diterima \\
X3 & .182 & 2.080 & .045 & Hipotesis diterima \\
\hline
\end{tabular}

a. Dependent Variable: Y

Sumber : Data diolah SPSS V.23.00 (2020)

Loyalitas Pegawai $=-0,598+0,531 X 1+0,443 X 2+0,182 X 3+e$

1. Koefisien variabel kepemimpinan transformasional dengan arah positif sebesar 0,531 yang berarti bahwa jika terjadi peningkatan kepemimpinan transformasional, maka loyalitas pegawai akan meningkat sebesar 0,531 . 
2. Koefisien variabel budaya organisasi dengan arah positif sebesar 0,443 yang berarti bahwa jika terjadi peningkatan budaya organisasi, maka loyalitas pegawai akan meningkat sebesar 0,443 .

3. Koefisien variabel kompensasi dengan arah positif sebesar 0,182 yang berarti bahwa jika terjadi peningkatan kompensasi, maka loyalitas pegawai akan meningkat sebesar 0,182 .

Output tabel 5 menunjukkan 1) kepemimpinan transformasional berpengaruh positif dan signifikan terhadap loyalitas pegawai dengan nilai statistik $\mathrm{t}$ hitung $>\mathrm{t}$ tabel $(5,709>1,689)$ dengan signifikan level 5\% artinya hipotesis pertama diterima. 2) budaya organisasi berpengaruh positif dan signifikan terhadap loyalitas pegawai dengan nilai statistik $t$ hitung $>\mathrm{t}$ tabel $(5,693>1,689)$ dengan signifikan level $5 \%$ artinya hipotesis kedua diterima. 3) kompensasi berpengaruh positif dan signifikan terhadap loyalitas pegawai dengan nilai statistik t hitung $>\mathrm{t}$ tabel $\quad(2,080>1,689)$ dengan signifikan level $5 \%$ artinya hipotesis ketiga diterima.

\section{PEMBAHASAN}

\section{Pengaruh KepemimpinanTransformasional Terhadap Loyalitas Pegawai}

Hasil pengujian hipotesis menemukan bahwa kepemimpinan transformasional positif signifikan memengaruhi loyalitas pegawai artinya kepemimpinan transformasional yang dilakukan pada instansi, dapat meningkatkan loyalitas pegawai begitupun sebaliknya jika kepemimpinan transformasional tidak dilakukan maka pegawai tidak akan memiliki loyalitas pada perusahaan. Keputusan yang diambil oleh pemimpin, dukungan yang diberikan kepada karyawan oleh pemimpin, komunikasi yang baik dari pemimpin, dan sikap pemimpin yang baik dapat mempengaruhi loyalitas karyawan agar kinerjanya baik. Pemimpin yang mampu memberikan kenyamanan kepada karyawannya berpengaruh positif terhadap loyalitas karyawan terhadap perusahaan.

Kusuma (2017) menyatakan bahwa kepemimpinan transformasional adalah suatu tindakan atau aktivitas yang secara sengaja mempengaruhi orang lain, untuk secara bersama-sama mencapai tujuan organisasi yang telah ditetapkan. Sebagai seorang pemimpin harus mampu menginterpretasikan kebutuhan yang ada dalam diri pengikutnya dan diri sendiri ke dalam tindakan.

Hasil penelitian (Jaya, 2018), (Utami \& Inayah, 2019) dan (Nurhidayanti. S \& Jumarding, 2020) membuktikan hal yang sama yaitu kepemimpinan transformasional berpengaruh positif dan signifikan terhadap loyalitas pegawai.

\section{Pengaruh Budaya Organisasi Terhadap Loyalitas Pegawai}

Hasil pengujian hipotesis menemukan bahwa budaya organisasi positif signifikan memengaruhi loyalitas pegawai artinya semakin tinggi budaya organisasi maka semakin tinggi pula loyalitas karyawan yang terbentuk, sebaliknya semakin rendah budaya organisasi maka semakin rendah loyalitas karyawan. Budaya organisasi sangat diperlukan dalam suatu perusahaan karena merupakan gagasan umum untuk 
meningkatkan loyalitas karyawan dan memudahkan karyawan mencapai tujuan perusahaan.

Hasil penelitian ini mendukung hasil penelitian (Sugiyarto, 2017), (Asriandi, Gani, \& Hasbi, 2018) dan (Rose, 2019) menemukan bahwa budaya organisasi berpengaruh signifikan terhadap loyalitas. (Lumingkewas, Adolfina, \& Uhing, 2019) menyatakan budaya organisasi yang memberikan kebebasan kepada karyawan untuk menjalankan tugasnya, atau tidak memberikan tekanan kepada mereka untuk menjalankan tugasnya, sehingga meningkatkan loyalitas pegawai dan berdampak positif pada kinerja mereka.

\section{Pengaruh Kompensasi Terhadap Loyalitas Pegawai}

Hasil pengujian hipotesis menemukan bahwa kompensasi berpengaruh positif signifikan terhadap loyalitas pegawai. Atinya, kompensasi yang dilakukan pada instansi, dapat meningkatkan loyalitas pegawai begitupun sebaliknya jika kompensasi tidak dilakukan. Dalam rangka mendorong atau memotivasi karyawan untuk bekerja dengan baik dan memiliki tingkat loyalitas yang tinggi, hal tersebut akan dipengaruhi oleh beberapa faktor, seperti dorongan pimpinan kepada karyawan. Karena keberhasilan organisasi tidak hanya dilihat dari loyalitas karyawan, tetapi juga kemampuan pimpinan dalam melaksanakan tanggung jawab atasan. Selain itu, kondisi lapangan menunjukkan bahwa tingkat loyalitas karyawan disebabkan oleh gaji dan kepemimpinan yang baik.

(Heryati, 2016) menyatakan bahwa pemberian kompensasi yang baik dan pencapaian kepuasan karyawan dapat meningkatkan loyalitas karyawan secara signifikan. Hasil penelitian ini mendukung hasil penelitian (Nor, 2016), (Widi, 2018) dan (Purnamasari \& Sintasasih, 2019) menemukan bahwa kompensasi berpengaruh positif dan signifikan terhadap loyalitas pegawai.

\section{KESIMPULAN}

Penelitian ini bertujuan untuk menguji dan menganalisis pengaruh kepemimpinan transformasional, budaya organisasi dan kompensasi terhadap loyalitas pegawaiDari rumusan masalah penelitian yang diajukan, maka analisis data yang telah dilakukan dapat ditarik beberapa kesimpulan, yaitu kepemimpinan transformasional, budaya organisasi dan kompensasi positif signifikan terhadap loyalitas pegawai.

\section{SARAN}

Penelitian ini menyarankan kepada PT Bosowa Berlian Motor (BBM) agar memperhatikan kompensasi pegawai untuk meningkatkan loyalitasnya kepada perusahaan. Penelitian ini juga menyarankan kepada peneliti selanjutnya agar menambah jumlah variabel baru selain variabel yang digunakan dalam penelitian ini agar lebih mengetahui unsur-unsur yang memengaruhi loyalitas pegawai. Hasil penelitian ini diharapkan agar dapat memberikan masukan dan pertimbangan bagi para manajer agar terus mempertahankan loyalitasnya agar tujuan perusahaan dapat tercapai. 
Asriandi, A., Gani, M. U., \& Hasbi, A. (2018). Pengaruh Budaya Organisasi dan Lingkungan Kerja Terhadap Loyalitas Karyawan Serta Dampaknya Terhadap Kinerja Karyawan PT Industri Kapal Indoenesia (Perseso). JEMMA. Journal of Economic, Management And Accounting, 1(2).

Dessler, G. (2015). Human Resource Management (14, 29th edition). Jakarta: Salemba Empat.

Djuraidi, A., \& Laily, N. (2020). Pengaruh Kepemimpinan Transformasional Terhadap Kinerja Karyawan Melalui Kepuasan Kerja Sebagai Variabel Moderating. Jurnal Riset Ekonomi dan Bisnis, 13(1).

Gunawan, F. (2017). Pengaruh Kompensasi dan Budaya Organisasi Terhadap Loyalitas Karyawan PT Victory Internasional Futures. AGORA, 5(1).

Heryati, A. (2016). Pengaruh Kompensasi dan Beban Kerja Terhadap Loyalitas Karyawan di Departemen Operasi PT Pupuk Sriwidjaja Palembang. $e$ journal.uigm.ac, 1(2).

Jaya, F. N. (2018, November). Pengaruh Kegiatan Prosedural, Gaya Kepemimpinan Transformasional dan Motivasi Kerja Terhadap Loyalitas Pegawai. Jurnal Ekobis Dewantara, 1(11).

Jogiyanto, H. (2014). Metodologi Penelitian Bisnis (salah kaprah dan pengalamanpengalaman). Yogyakarta: BPFE.

Lumingkewas, G., Adolfina, \& Uhing, Y. (2019, Juli). Analisis Pengaruh Budaya Organisasi dan Loyalitas Terhadap Kinerja Karyawan Bank Sulut-Go Kantor Cabang Tomohon. Jurnal EMBA, 7(6).

Marzuki, F. (2018, Mei). Pengaruh Gaya Kepemimpinan Transformasional san Profesionalisme Kerja Terhadap LOyalitas Karyawan di LP3I Group. Jurnal Lentera Bisnis, 7(1).

Nor, R. J. (2016). Pengaruh Gaya Kepemimpinan dan Kompensasi Terhadap Loyalitas Kerja Karyawan Bebek Goreng Kalijo Banjarmasin. Jurnal Ilmiah Mahasiswa Universitas Brawijaya, 5(2).

Nurhidayanti. S, \& Jumarding, A. (2020, April s/d Juni). Analisis Gaya Kepemimpinan Terhadap Loyalitas Karyawan Di Direktorat Pembinaan Pendidikan di Kementerian Pendidikan dan Kebudayaan. Economics Bosowa Journal, XXXIV.

Purnamasari, N. D., \& Sintasasih, D. K. (2019). Pengaruh Pengembangan Karir, Kompensasi dan Iklim Organisasi Terhadap Loyalitas Karyawan. E-Jurnal Manajemen, 8(9).

Rose, V. (2019). Pengaruh Budaya Organisasi Terhadap Loyalitas Karyawan Melalui Komitmen Organisasional Sebagai Variabel Intervening. Management and Business Review, 3(2).

Saptarini, P. D., \& Yudhaningsih, N. (2020). Peranan Kepuasan Kerja Dalam Dalam Memediasi Pengaruh Kompensasi Terhadap Loyalitas Karyawan Pada PT Pratama Asia Sejahtera. Jurnal Ilmiah Satyagraha, 3(1).

Sugiyarto, S. (2017). Pengaruh Budaya Organisasi dan Kepemimpinan Terhadap Loyalitas Karyawan Pada PT Purnamajaya Bhakti Utama. Jurnal Sekretari. Universitas Pamulang., 4(2). 
Utami, I. R., \& Inayah. (2019, Oktober). Pengaruh Gaya Kepemimpinan Transformasional dan Komitmen Organisasi Terhadap Loyalitas Karyawan Hazotel Semarang. Jurnal JOBS, 5(1).

Widi, R. A. (2018, Juni). Studi Kompensasi dan Lingkungan Kerja Terhadap Loyalitas Karyawan Berdampak Pada Kinerja Karyawan. Upajiwa Dewantara Vol. 2 No.1, 2(1). 